\title{
Adolescent Body Perception: Urban, Rural and Suburban Differences
}

\author{
Molly M. Jacobs* \\ Health Services and Information Management, East Carolina University, 600 Moye Blvd Mail Stop 668, Health \\ Sciences Building 4340E, Greenville NC, 27834
}

*Corresponding Author: Molly M. Jacobs, Health Services and Information Management, East Carolina University, 600 Moye Blvd Mail Stop 668, Health Sciences Building 4340E, Greenville NC, 27834,USA, Email: Jacobsm17@ecu.edu

\begin{abstract}
Introduction: Body weight perception refers to the personal evaluation of one's weight irrespective of actual BMI. Body perception does not always reflect reality and can be influenced external factors.

Methods: This paper explores the association between adolescents' body perception, demographic characteristics and residential location using both binary and multinomial logistic regression analysis to assess 1) perception accuracy, 2) the association between demographic characteristics and perception accuracy and 3) the relationship between perception and residence,
\end{abstract}

Results: Results showed that half of adolescents misestimate (either under or over categorize) their body weight and that discordant perception is more prevalent among men, the overweight, blacks, younger adolescents and those enrolled in school. The type of misestimation varies by residential location. Rural residents are less likely to overestimate their weight while suburban residents are more like to underestimate their body weight compared to urban residents.

Discussion and Conclusion: By examining both over estimation and underestimation of body weight, this study identified trends in adolescent weight perception by region. Rural residents are less likely to over-and suburban residents are more like to over-estimate their body weight compared to urban dwellers. Both are problematic. Underestimation can signify that actual overweight is being ignored. Overestimation may motivate overweight youth to eat healthier and be more active but could encourage unhealthy weight control behaviors. Therefore, intervention programs should be careful to promote healthy weight and weight perception.

\section{INTRODUCTION}

Body weight perception refers to the personal evaluation of one's weight as "underweight" or "normal weight" or "overweight" irrespective of actual body mass index (BMI) [1,2]. However, one's perception does not always reflect reality [3] and can be influenced by external factors including family, media, and advertisements $[4,5]$. Geographic location likely has an impact on self-perception because of varying environmental, social and media influences [6]. Peers or classmates could also potentially influence perception due to social influences [716]. Weight perception influences individuals' weight concerns or lack thereof $[17,18]$. It can be positive motivating healthy weight maintenance, exercise and diet [19] or negative leading to unhealthy thoughts, feelings or behaviors [17,18]. Evidence suggests that perceived body weight is strongly correlated with body actual weight and emotional satisfaction/depression.

Literature on adolescent weight-perception suggests that regional differences also play a role in weight perception and in weightmanagement goals and practices [20]. In general, individuals living in large cities seem to engage in better health-promoting behaviors [21]. Findings on rural-urban differences in perception have been inconsistent [22], showing variation in weight-related behaviors rather than one's view of own weight [23]. To date, no studies have identified systematic perception tendencies among urban, suburban and rural adolescent males and females [17, 24-28] using a nationally representative sample. 
As individuals begin to establish their selfimage during these adolescent years, it is important to understand the role these external factors [29,30] play in body perception or misperception to gain a better understanding of adolescent health awareness and how to promote health [17,31,32]. Controlling for various sociodemographic, physical, environmental, behavioral and household characteristics, this study analyzes the differences in body misperception by residence and weight. Using a nationally representative sample, data shows systematic patterns in under-, over- and accurate weight estimation among adolescents in urban, rural and suburban adolescents.

This paper explores the association between adolescents' weight misperception, demographic characteristics and residential location. With the hypothesis that adolescents fail to correctly identify their weight status, underestimating their weight and that misperceptions are larger among females, this study proceeds with a discussion of the current research on this topic in Section II. Section III describes the data and methodology, while Section IV outlines the empirical results. Finally, Section V outlines how these results could be used to shape policies and provides concluding remarks.

\section{BACKGROUND}

Body perception research has typically been limited by 1) weight control behaviors focus restricted predominately to the effects of race/ethnicity and gender; 2) failure to control for objective weight status; and/or 3) a sample restricted to certain regions or group [17,3341]. There is a great deal of literature concerning the relationship between adolescents' weight perception and their weight control strategies $[17,26,27,42]$. Some studies indicate that adolescents who view themselves as being overweight are more likely to intend to lose weight but less likely to be physically active than those who perceive themselves as being normal weight [24,27]. Others have found that perceiving oneself as overweight may be associated with more physical activity and greater tendency for extreme weight loss behavior than perceiving oneself as being normal weight [42]. Studies are inconsistent in the behaviors and characteristics they find associated with overweight [25], normal weight and underweight $[17,27]$. Research suggests that body image and weight concerns are more important among females and they are more likely to try smoking, excessive exercise or diet restrictions to lose weight than males [43,44]. Females also appear more susceptible than males to peer influences on health-related behaviors [45, 46]; however, males appear more likely to be influenced by risk-taking behaviors [44].

Previous studies note that self-perceived weight status is inadequately explained by actual body size [43-48]. A sizable fraction of normal-weight individuals attempts or desire weight loss, while an equally notable fraction of overweight peopleis not [45,46,49-55]. Self-evaluation of weight status, however, is not simply an autonomous, individual response; it is likely subject to social patterning and environmental influences. Attitudes toward body size and preferences for distinct levels of fatness are mediated by local social and cultural factors, and perceptions may vary in predictable ways among population subgroups [56].

This work improves on previous studies in several ways. First, this study adjusts for a broad range of sociodemographic factors including race/ethnicity, household income and age. Second, Add Health data consists of a nationally representative sample of adolescents and measures weight at various intervals throughout their development. Since BMI is interpreted as a percentile for individuals below 20 and as a raw value for those above 20, this study incorporates the appropriate BMI-age standard and utilizes the categorical measure in the estimation function. Additionally, various statistical tools from $\mathrm{X}^{2}$ statistics to ANOVA to multinomial logistics regressions tested these relationships and all showed consistent findings. Finally, care was taken to normalize the BMI distribution, reducing any potential bias due to under- or over-reporting at BMI extremes [57,58]. Given the inconsistent and sparse evidence on the relationship between weight perception and exogeneous influences, it is important to understand any misperception bias in relation to residential location.

\section{MATERIALS AND METHODS}

This study compares weight misperception of urban, rural and suburban adolescents using four waves from the National Longitudinal Study of Adolescent to Adult Health (Add Health) - a nationally representative sample of adolescents age 10 to 19 years old. These four waves were collect in 1994-1995, 1996, 2001-2002 and 2008. Respondents were surveyed in their homes to collect data on respondents' social, economic, psychological and physical well- 
being with contextual data on the family, neighborhood, community, school, and relationships, providing a unique opportunity to asses show urban, rural and suburban respondents systematically underestimate, accurately estimate of overestimate their weight status. All waves include in-home interviews as well as contextual variables on income and poverty, unemployment, availability and utilization of health services, crime, church membership, and social programs and policies.

Add Health was created to help research the causes of adolescent health and health behavior with a special emphasis on the effects of multiple contexts of adolescent life [33]. Basic demographic characteristics - gender, age, race, ethnicity, height and weight - were obtained in all waves. Age is listed as the age in years at the time the survey was conducted. Respondents self-classify their race and ethnicity. For this analysis two dummy variables-black and Hispanic-capture between 18 and 13 percent, respectively, of the sample. Household income measures total income, pre-tax income in 1995 including income, income of everyone else in the household, and income from welfare benefits, dividends, and all other sources. This was obtained from the parental questionnaire and translated into a dummy variable equaling 1 if income is greater than $\$ 700$ and zero if otherwise.

Respondents report whether they are currently enrolled in school or, if the interview is conducted during the summer, whether they were enrolled in school in the past school year. They are also asked to classify their weight as very underweight, slightly underweight, normal weight, slightly overweight or very overweight. This item is used as the measure of weight perception. For this analysis, the two underweight categories - very underweight and slightly underweight - are combined into one group. Interviewers characterized the immediate area or street where respondent lives as rural, suburban, urban- mostly residential, urban- 3 or more commercial properties, mostly retail or urban- 3 or more commercial properties, mostly wholesale or industrial. All the urban classifications are combined into one group.

Self-reported height and weight were used to calculate BMI. BMI was used to place all respondents into BMI categories - underweight, normal weight, overweight and obese. For respondents age 19 and below, BMI percentiles were used to place individuals into weight categories. BMI percentiles, developed by the Centers for Disease Control and Prevention, assign each respondent a percentile ranking based on their stature compared to others on of the same age using gender-specific BMI-for-age growth charts. Respondents are categorized based on their BMI score. The corresponding categories are listed in Table I. Categories, rather than BMI values, were used to classify individuals.

Table I. BMI Categorical Classification

\begin{tabular}{|l|l|l|}
\hline \multicolumn{1}{|c|}{$\begin{array}{c}\text { Weight Status } \\
\text { Category }\end{array}$} & \multicolumn{1}{|c|}{ Percentile } & BMI \\
\hline Age & $>=2,<=19$ & $>=20$ \\
\hline Underweight & $<5$ th & $<18.5$ \\
\hline $\begin{array}{l}\text { Normal or Healthy } \\
\text { Weight }\end{array}$ & $>=5$ th, $<85$ th & $\begin{array}{l}>=18.5, \\
<25\end{array}$ \\
\hline Overweight & $>=85$ th, & $\begin{array}{l}>=25, \\
<30\end{array}$ \\
\hline Obese & $>95$ th & $>=30$ \\
\hline
\end{tabular}

Table II list the mean and frequency distributions for BMI category, weight perception and demographic variables for men and women, which are listed separately. Forty to 50 percent, of men and women perceive their weight as normal and a slightly smaller proportion, 30 to 40 percent, perceive overweight. There are relatively few who see themselves are underweight or obese. Interestingly, more females than males perceive themselves and overweight and nearly 10 percent of females perceive themselves as obese. These percentages differ largely from the actual BMI categories which show that about twenty percent of the sample is obese and 20 to 25 percent are overweight. Both gender drastically underestimate their true weight particularly males.

TableII. Sociodemographic Characteristics Means and Frequencies

\begin{tabular}{|l|r|r|r|r|}
\hline \multicolumn{5}{|c|}{$\begin{array}{c}\text { Sociodemographic Characteristics Means and } \\
\text { Frequencies }\end{array}$} \\
\hline & N & \multicolumn{1}{c|}{ Percent } & \multicolumn{1}{c|}{ N } & Percent \\
\hline & \multicolumn{5}{c|}{ Male } & Female \\
\hline \multicolumn{5}{|c|}{ Perception } \\
\hline Underweight & 780 & 18.3896 & 462 & 8.0903 \\
\hline $\begin{array}{l}\text { Normal } \\
\text { Weight }\end{array}$ & 2116 & 49.2663 & 2385 & 43.2121 \\
\hline Overweight & 1209 & 28.7461 & 2111 & 39.3268 \\
\hline Obese & 154 & 3.598 & 516 & 9.3708 \\
\hline \multicolumn{5}{|c|}{ BMI Category } \\
\hline Underweight & 70 & 1.7706 & 493 & 9.25 \\
\hline $\begin{array}{l}\text { Normal } \\
\text { Weight }\end{array}$ & 2331 & 52.2787 & 2967 & 54.1562 \\
\hline Overweight & 1054 & 24.824 & 1054 & 19.2456 \\
\hline Obese & 904 & 21.1267 & 955 & 17.3483 \\
\hline
\end{tabular}




\begin{tabular}{|c|c|c|c|c|}
\hline \multicolumn{5}{|c|}{ Race/Ethnicity } \\
\hline Black & 861 & 13.3829 & 1432 & 16.9116 \\
\hline Hispanic & 517 & 13.9563 & 608 & 13.8332 \\
\hline High Income & 571 & 13.9593 & 673 & 13.9945 \\
\hline In School & 2667 & 62.6825 & 3549 & 63.9675 \\
\hline \multicolumn{5}{|c|}{ Exercise } \\
\hline Never & 963 & 27.8697 & 792 & 17.2721 \\
\hline 1 or 2 times & 977 & 27.7174 & 1624 & 34.7213 \\
\hline 3 or 4 times & 671 & 19.0609 & 1115 & 23.8687 \\
\hline $\begin{array}{l}5 \text { or more } \\
\text { times }\end{array}$ & 891 & 25.352 & 1173 & 24.1378 \\
\hline \multicolumn{5}{|c|}{ Residence } \\
\hline Rural & 704 & 23.0201 & 936 & 23.9239 \\
\hline Suburban & 984 & 32.5283 & 1140 & 29.0782 \\
\hline Urban & 3037 & 44.4516 & 1848 & 46.9979 \\
\hline \multicolumn{5}{|c|}{ Descriptive Statistics of Demographic Variables } \\
\hline Variable & Mean & $\mathrm{M}$ & & Max \\
\hline \multicolumn{5}{|c|}{ Male } \\
\hline $\begin{array}{l}\text { Age } \\
\text { Wave I }\end{array}$ & 14.868932 & & 10 & 19 \\
\hline TV & 15.587268 & & 0 & 998 \\
\hline \multicolumn{5}{|c|}{ Female } \\
\hline $\begin{array}{l}\text { Age } \\
\text { Wave I }\end{array}$ & 14.679133 & & 11 & 19 \\
\hline TV & 14.511108 & & 0 & 998 \\
\hline
\end{tabular}

About one-third are self-designated as black or Hispanic and less than 15 percent are from high income households. Most respondents, 60 percent, are enrolled in school. Less than half of males and females live in urban areas, while 25 percent reside in rural towns and about a quarter in the suburbs. Age is represented as the age in the first sample, Wave I, and range from 10 to 19.

Table III provides correlation coefficients between misperception and all demographic and lifestyle covariates. Misperception is highly, positively correlated with BMI, age, residence and being black or Hispanic. Positive correlation would denote a higher likelihood of either over or underestimating one's weight. It is negatively correlated with school enrollment, indicating that those enrolled in school are more likely to accurately classify their body weight.

Table III. Male and Female Correlation Coefficients

\begin{tabular}{|c|c|c|c|c|c|c|c|c|c|}
\hline \multicolumn{10}{|c|}{ Male and Female Correlation Coefficients } \\
\hline \multicolumn{10}{|c|}{ 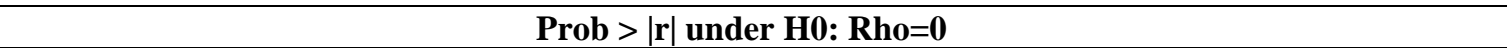 } \\
\hline \multicolumn{10}{|c|}{ Number of Observations } \\
\hline \multirow{9}{*}{ 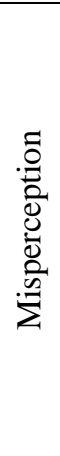 } & BMI & Age & $\begin{array}{c}\text { In } \\
\text { School }\end{array}$ & Residence & Exercise & Black & Hispanic & TV & $\begin{array}{l}\text { High } \\
\text { Income }\end{array}$ \\
\hline & \multicolumn{9}{|c|}{ Male } \\
\hline & 0.35786 & 0.29549 & -0.22289 & 0.08998 & -0.07686 & 0.06808 & -0.04021 & $\begin{array}{r}- \\
0.02565\end{array}$ & -0.00112 \\
\hline & $<.0001$ & $<.0001$ & $<.0001$ & $<.0001$ & $<.0001$ & $<.0001$ & 0.0138 & 0.095 & 0.9469 \\
\hline & 4258 & 4258 & 4255 & 3036 & 3501 & 4258 & 3748 & 4240 & 3513 \\
\hline & \multicolumn{9}{|c|}{ Female } \\
\hline & 0.39659 & 0.22481 & -0.19357 & 0.12019 & -0.02731 & 0.15183 & 0.03297 & 0.05128 & -0.04508 \\
\hline & $<.0001$ & $<.0001$ & $<.0001$ & $<.0001$ & 0.0612 & $<.0001$ & 0.023 & 0.0002 & 0.003 \\
\hline & 5469 & 5469 & 5468 & 3921 & 4699 & 5469 & 4752 & 5452 & 4320 \\
\hline
\end{tabular}

Table IV list the percentage of residential groups that under; over and accurately estimate their body size. Fifty to sixty percent of males and females respectively perceive their body size. The remaining fifty percent either over or underestimates their body size. Females tend to underestimate body size and males overestimate. It is difficult to discern distinct differences in perception among rural, urban and suburban youth. Suburban residents appear to have the highest frequency of underestimation and urban residents the highest rate of overestimation. These frequencies suggestion systematic differences in perception accuracy among residential locations.

This study uses regression analysis to assess 1) adolescent perception accuracy, 2) the association between demographic characteristics and perception accuracy and 3) the relationship between misperception and residence. The first estimation model, a binary logistic regression, explores whether adolescents accurately assess their body weight and the contributors. The second model, a multinomial logistic regression, evaluates the difference between over, underand accurate weight estimation and what leads to these to these types of weight discordance. To test for different behavior along the BMI distribution, both models were run on the full sample then separately on overweight/obese respondents and normal/underweight respondents. SAS 9.4 (SAS Institute Inc, Cary, North Carolina) was used to carry out the statistical analyses. 
TableIV. Residence and Misperception Distributions

\begin{tabular}{|l|r|r|r|}
\hline \multicolumn{5}{|c|}{ Residence and Misperception Distributions } \\
\hline \multirow{2}{*}{$\begin{array}{l}\text { Row Pct } \\
\text { Col Pet }\end{array}$} & \multicolumn{3}{|c|}{ Misperception } \\
\cline { 2 - 4 } & Underestimate & $\begin{array}{c}\text { Accurately } \\
\text { Estimate }\end{array}$ & Overestimate \\
\hline \multicolumn{4}{|c|}{ Male } \\
\hline Rural & 10.16 & 58.28 & 31.56 \\
& 25.51 & 24.37 & 20.73 \\
\hline Suburban & 11.21 & 58.21 & 30.58 \\
& 38.48 & 33.29 & 27.46 \\
\hline Urban & 7.38 & 52.07 & 40.56 \\
& 36.01 & 42.34 & 51.8 \\
\hline & Female \\
\hline Rural & 29.02 & 58.32 & 12.66 \\
& 27.22 & 22.83 & 18.96 \\
\hline Suburban & 29.15 & 58.23 & 12.62 \\
& 34.96 & 29.15 & 24.16 \\
\hline Urban & 20.06 & 61.04 & 18.91 \\
& 37.81 & 48.02 & 56.88 \\
\hline
\end{tabular}

\section{RESULTS}

Table V lists results from binary logistic regression. The dependent variable measures

Table V. Logit of Misperception on Residence and Demographic Characteristics whether perception aligns with BMI category, assuming a value of one if they are discordant and zero if they are concordant. Age, being overweight, school enrollment, gender and residence are significant. By taking the exponential of the coefficient, the estimate can then be interpreted as the impact of the independent variable on the log-odds. Using this simple conversion, results show that males have a higher probably of discordant perception as do those who are overweight and enrolled in school. Older respondents are less likely to be discordant suggesting that ability to assess one's weight increases with age. Estimates also test whether urban, rural and suburban residence impacts weight discordance. Compared to the urban reference category, suburban residents appear more like to view their weight inaccurately.

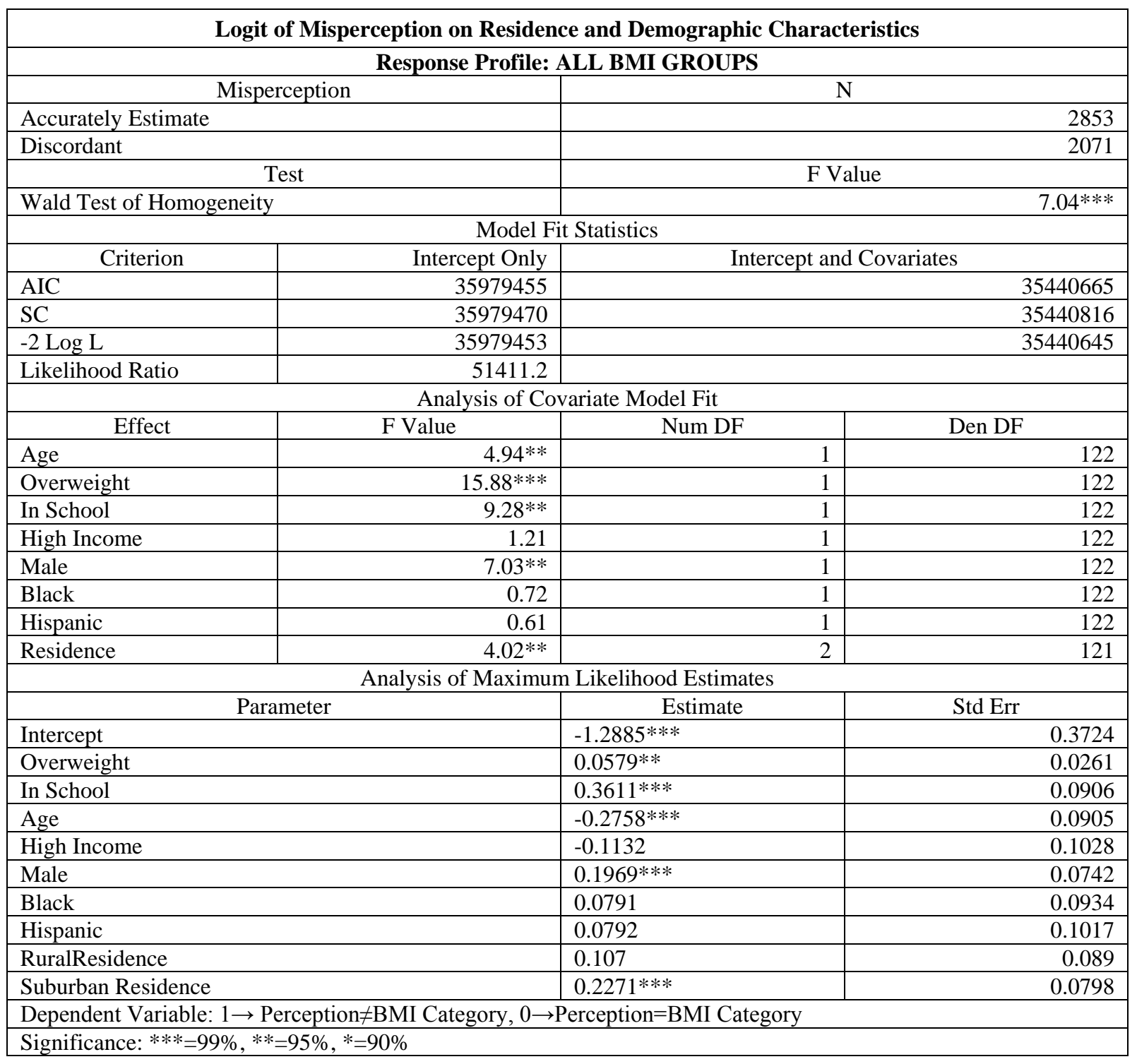


These results provide some insight into adolescent body perception, but do not provide information into the type of weight discordance. Therefore, the second set of results, listed in Table VI, include a multinomial logistic model. The dependent variable assumes a value of one for overestimation, zero for accurate estimation and negative one for underestimation. Accurate weight estimation serves as the reference category. Results are relatively consistent with those presented above. Age, overweight, school enrollment, gender and residence continue to be deterministic, but black and Hispanic also emerge as significant. Coefficients model the probability of over and underestimating body weight relative to accurately estimating - the reference category. The exponential of the estimate represents the impact of the independent variable on the log-odds of under or over estimating their body weight.

Table VI. Multinomial Logit of Misperception on Residence and Demographic Characteristics

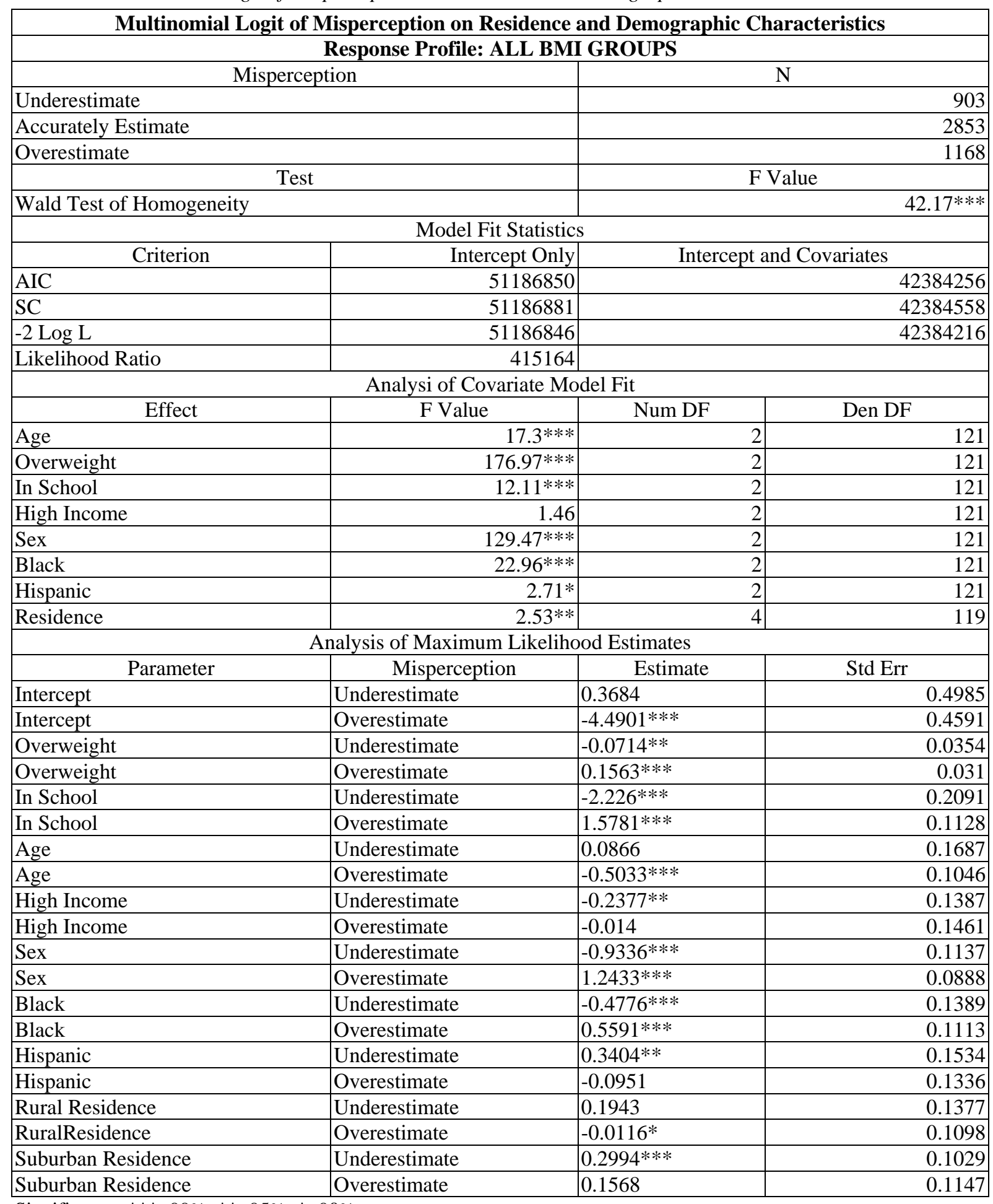

Significance: $* * *=99 \%, * *=95 \%, *=90 \%$

Dependent Variable: $-1=$ Underestimation, $0=$ Accurate Estimation, $1=$ Overestimation 
Overweight respondents are less likely to underestimate and more likely to overestimate their body size. Bivariate logit results showed that older respondents were less likely to experience perception discordance. These multinomial estimates showed that younger respondents are twice as likely to perceive themselves overweight as older ones. Those enrolled in school are less likely to underestimate and males are three times more likely to overestimate their weight than females. Blacks are twice as likely to overestimate their body size, while Hispanics underestimate, compared to other groups. In the earlier specification, suburban residents were distinctly different, but rural residents were not. When the type of discordance is disaggregated, both residential categories show distinctively different behavior. Rural residents are less likely than urban residents to overestimate their weight while suburban residents are more likely to underestimate their body weight. These results are supported by mean analysis presented earlier Appendix I

\begin{tabular}{|c|c|c|c|}
\hline \multicolumn{4}{|c|}{ Logit of Misperception on Residence and Demographic Characteristics } \\
\hline \multicolumn{4}{|c|}{ Response Profile:NORMAL WEIGHT } \\
\hline \multicolumn{2}{|c|}{ Misperception } & \multicolumn{2}{|l|}{ (1) } \\
\hline \multicolumn{2}{|c|}{ Accurately Estimate } & & 1982 \\
\hline \multicolumn{2}{|l|}{ Discordant } & \multirow{2}{*}{\multicolumn{2}{|c|}{ F Value }} \\
\hline \multicolumn{2}{|c|}{ Test } & & \\
\hline \multicolumn{2}{|c|}{ Wald Test of Homogeneity } & \multicolumn{2}{|r|}{$2.55 * * *$} \\
\hline \multicolumn{4}{|c|}{ Model Fit Statistics } \\
\hline Criterion & Intercept Only & \multicolumn{2}{|c|}{ Intercept and Covariates } \\
\hline AIC & 22842457 & & 22665165 \\
\hline $\mathrm{SC}$ & 22842471 & & 22665297 \\
\hline$-2 \log L$ & 22842455 & & 22665147 \\
\hline Likelihood Ratio & 18396.8 & & \\
\hline \multicolumn{4}{|c|}{ Analysis of Covariate Model Fit } \\
\hline Effect & Value & Num DF & Den DF \\
\hline Age & 2.46 & 1 & 122 \\
\hline In School & 1.04 & 1 & 122 \\
\hline High Income & $3.33^{*}$ & 1 & 122 \\
\hline Male & $4.43 * *$ & 1 & 122 \\
\hline Black & $3.66 * *$ & 1 & 122 \\
\hline Hispanic & 1.39 & 1 & 122 \\
\hline Residence & $4.73 * *$ & 2 & 121 \\
\hline \multicolumn{4}{|c|}{ Analysis of Maximum Likelihood Estimates } \\
\hline \multicolumn{2}{|c|}{ Parameter } & Estimate & Std Err \\
\hline Intercept & & $-1.0194 * *$ & 0.4711 \\
\hline In School & & 0.0505 & 0.0322 \\
\hline Age & & -0.1476 & 0.1448 \\
\hline High Income & & $-0.2366^{*}$ & 0.1298 \\
\hline Male & & $-0.2058 * *$ & 0.0977 \\
\hline Black & & $-0.2264 * *$ & 0.1183 \\
\hline Hispanic & & 0.1849 & 0.1569 \\
\hline RuralResidence & & -0.0129 & 0.1122 \\
\hline Suburban Residence & & $0.2376 * *$ & 0.0877 \\
\hline
\end{tabular}

showing that a substantial proportion of urban residents who overestimate, rural residents accurately estimate, and suburban residents underestimate their body weight. Research shows that the sociodemographic factors working in urban and rural areas manifest distinctly differently and could contribute to varying self-views [59]. Not only do adolescents in different residential locations have varying lifestyles, but they also hold different body size ideals [60].

While distinct regional differences in perception accuracy exist among the full sample, it is important to test whether these results vary along the BMI distribution. To check for discontinuity, the sample was divided into two groups - overweight and normal weight. Regression analysis was repeated on the two groups. Results from the bivariate logit can be found in Appendix I and results from the multinomial logit are listed in Appendix II 
Adolescent Body Perception: Urban, Rural and Suburban Differences

\begin{tabular}{|c|c|c|}
\hline \multicolumn{3}{|l|}{ Significance: $* * *=99 \%, * *=95 \%, *=90 \%$} \\
\hline \multicolumn{3}{|c|}{ Logit of Misperception on Residence and Demographic Characteristics } \\
\hline \multicolumn{3}{|c|}{ Response Profile: OVERWEIGHT } \\
\hline Misperception & \multicolumn{2}{|c|}{$\mathrm{N}$} \\
\hline Accurately Estimate & \multicolumn{2}{|r|}{871} \\
\hline Discordant & \multicolumn{2}{|r|}{853} \\
\hline Test & \multicolumn{2}{|c|}{ F Value } \\
\hline Wald Test of Homogeneity & & $12.9 * * *$ \\
\hline \multicolumn{3}{|c|}{ Model Fit Statistics } \\
\hline Intercept Only & \multicolumn{2}{|c|}{ Intercept and Covariates } \\
\hline 12823836 & & 12115383 \\
\hline 12823850 & & 12115510 \\
\hline 12823834 & & 12115365 \\
\hline Likelihood Ratio & & \\
\hline \multicolumn{3}{|c|}{ Analysis of Covariate Model Fit } \\
\hline F Value & Num DF & Den DF \\
\hline 2.35 & 1 & 119 \\
\hline In School & 1 & 119 \\
\hline High Income & 1 & 119 \\
\hline $80 * * *$ & 1 & 119 \\
\hline $19.19 * * *$ & 1 & 119 \\
\hline Hispanic & 1 & 119 \\
\hline Residence & 2 & 118 \\
\hline \multicolumn{3}{|c|}{ Analysis of Maximum Likelihood Estimates } \\
\hline Parameter & Estimate & Std Err \\
\hline Intercept & $-1.4444 * *$ & 0.5749 \\
\hline In School & 0.0607 & 0.0396 \\
\hline Age & $-0.4449 * * *$ & 0.1132 \\
\hline High Income & 0.1285 & 0.1847 \\
\hline Male & $0.9852 * * *$ & 0.1102 \\
\hline Black & $0.7284 * * *$ & 0.1663 \\
\hline Hispanic & -0.0564 & 0.1787 \\
\hline RuralResidence & $0.3408 * *$ & 0.1395 \\
\hline Suburban Residence & 0.153 & 0.1541 \\
\hline \multicolumn{3}{|c|}{ Dependent Variable: $1 \rightarrow$ Perception $\neq$ BMI Category, $0 \rightarrow$ Perception=BMI Category } \\
\hline \multicolumn{3}{|l|}{ Significance: $* * *=99 \%, * *=95 \%, *=90 \%$} \\
\hline
\end{tabular}

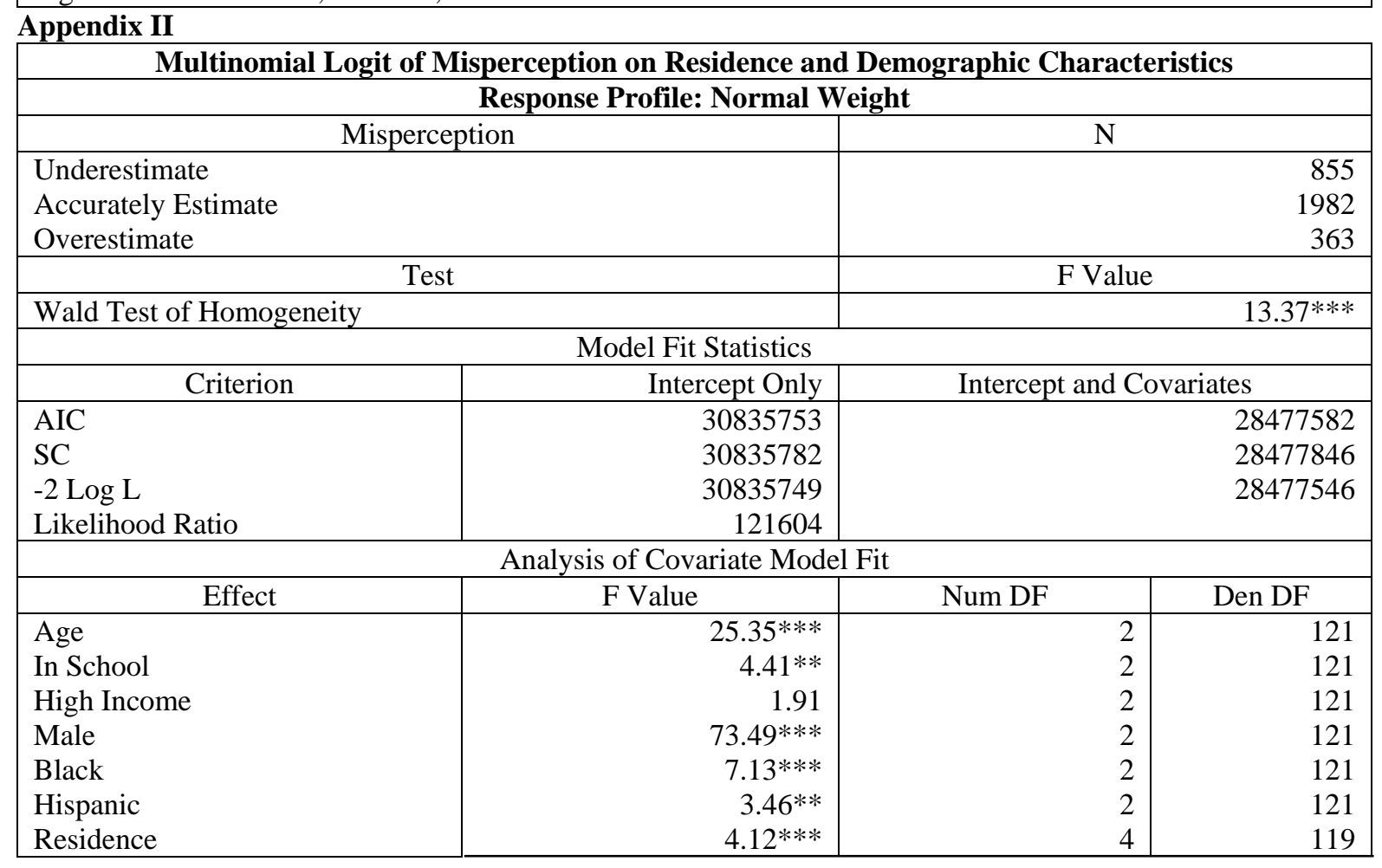


Adolescent Body Perception: Urban, Rural and Suburban Differences

\begin{tabular}{|c|c|c|c|}
\hline \multicolumn{4}{|c|}{ Analysis of Maximum Likelihood Estimates } \\
\hline Parameter & Misperception & Estimate & Std Err \\
\hline Intercept & Underestimate & 0.477 & 0.5292 \\
\hline Intercept & Overestimate & $-6.9598 * * *$ & 0.8222 \\
\hline Age & Underestimate & $-0.0775 * *$ & 0.0376 \\
\hline Age & Overestimate & $0.3277 * * *$ & 0.0522 \\
\hline In School & Underestimate & 0.0533 & 0.1851 \\
\hline In School & Overestimate & $-0.5042 * *$ & 0.1832 \\
\hline High Income & Underestimate & $-0.2691 *$ & 0.1464 \\
\hline High Income & Overestimate & -0.2241 & 0.21 \\
\hline Male & Underestimate & $-0.8852 * * *$ & 0.1159 \\
\hline Male & Overestimate & $1.506 * * *$ & 0.1722 \\
\hline Black & Underestimate & $-0.4997 * * *$ & 0.1433 \\
\hline Black & Overestimate & 0.1771 & 0.1938 \\
\hline Hispanic & Underestimate & $0.3606 * *$ & 0.1721 \\
\hline Hispanic & Overestimate & -0.2784 & 0.2637 \\
\hline Rural Residence & Underestimate & 0.1265 & 0.1406 \\
\hline RuralResidence & Overestimate & $-0.4294 * * *$ & 0.1984 \\
\hline Suburban Residence & Underestimate & $0.3162 * * *$ & 0.1068 \\
\hline Suburban Residence & Overestimate & 0.071 & 0.1668 \\
\hline
\end{tabular}

\begin{tabular}{|c|c|c|c|}
\hline \multirow{2}{*}{\multicolumn{4}{|c|}{$\begin{array}{c}\text { Multinomial Logit of Misperception on Residence and Demographic Chara } \\
\text { Response Profile: Overweight }\end{array}$}} \\
\hline & & & \\
\hline \multicolumn{2}{|c|}{ Misperception } & \multicolumn{2}{|c|}{$\mathrm{N}$} \\
\hline \multirow{3}{*}{\multicolumn{2}{|c|}{$\begin{array}{l}\text { Underestimate } \\
\text { Accurately Estimate } \\
\text { Overestimate }\end{array}$}} & \multicolumn{2}{|r|}{48} \\
\hline & & \multicolumn{2}{|r|}{871} \\
\hline & & & 805 \\
\hline \multicolumn{2}{|c|}{ Test } & \multicolumn{2}{|c|}{ F Value } \\
\hline \multicolumn{2}{|l|}{ Wald Test of Homogeneity } & \multirow{2}{*}{\multicolumn{2}{|c|}{$9.51 * * *$}} \\
\hline \multicolumn{2}{|r|}{ Model Fit Statistics } & & \\
\hline \multicolumn{2}{|r|}{ Intercept Only } & \multicolumn{2}{|c|}{ Intercept and Covariates } \\
\hline $\mathrm{AIC}$ & 14629133 & \multirow{4}{*}{\multicolumn{2}{|c|}{$\begin{array}{l}13497022 \\
13497275 \\
13496986\end{array}$}} \\
\hline $\mathrm{SC}$ & 14629161 & & \\
\hline$-2 \log \mathrm{L}$ & 14629129 & & \\
\hline Likelihood Ratio & 63639.1 & & \\
\hline \multicolumn{4}{|c|}{ Analysis of Covariate Model Fit } \\
\hline Effect & F Value & Num DF & Den DF \\
\hline Age & $2.86 *$ & (1) & 118 \\
\hline In School & $9.54 * * *$ & 2 & 118 \\
\hline High Income & 0.23 & 2 & 118 \\
\hline Male & $63.8 * * *$ & 2 & 118 \\
\hline Black & $12.49 * * *$ & 2 & 118 \\
\hline Hispanic & 0.05 & 2 & 118 \\
\hline Residence & $2.26^{*}$ & 4 & 116 \\
\hline \multicolumn{4}{|c|}{ Analysis of Maximum Likelihood Estimates } \\
\hline Parameter & Misperception & Estimate & Std Err \\
\hline Intercept & Underestimate & $-6.7449 * * *$ & 1.8868 \\
\hline Intercept & Overestimate & $-1.3819 * *$ & 0.5832 \\
\hline Age & Underestimate & $0.2676 * *$ & 0.1181 \\
\hline Age & Overestimate & 0.0466 & 0.0407 \\
\hline In School & Underestimate & 0.3226 & 0.3915 \\
\hline In School & Overestimate & $-0.493 * * *$ & 0.116 \\
\hline High Income & Underestimate & 0.162 & 0.5504 \\
\hline High Income & Overestimate & 0.1255 & 0.1872 \\
\hline Male & Underestimate & $-1.8012 * * *$ & 0.5274 \\
\hline Male & Overestimate & $1.1376^{* * *}$ & 0.1111 \\
\hline Black & Underestimate & -0.8538 & 0.6949 \\
\hline Black & Overestimate & $0.8237 * * *$ & 0.1725 \\
\hline Hispanic & Underestimate & -0.0609 & 0.4908 \\
\hline
\end{tabular}




\begin{tabular}{|l|l|l|r|}
\hline Hispanic & Overestimate & -0.0546 & 0.1833 \\
Rural Residence & Underestimate & $0.7279 * *$ & 0.3549 \\
RuralResidence & Overestimate & $0.296^{* *}$ & 0.1415 \\
Suburban Residence & Underestimate & -0.1574 & 0.441 \\
Suburban Residence & Overestimate & 0.1728 & 0.1592 \\
\hline
\end{tabular}

Significance: $* * *=99 \%, * *=95 \%, *=90 \%$

Dependent Variable: $-1=$ Underestimation, $0=$ Accurate Estimation, 1=Overestimation

In the binary logit of discordance, coefficient for age, sex, race, ethnicity and school enrollment remain significant and consistent among the normal and overweight groups. Normal weight suburban adolescents and overweight rural adolescents are more likely to be discordant. While rural was not significant in the previous specification, these results are consistent with the multinomial estimate that shows both rural and suburban differentials.

In the multinomial log it of estimation accuracy, gender, age, overweight, school enrollment, race and ethnicity continue to be deterministic and the impacts remain similar. Both rural and suburban residents continue to misestimate weight on both the normal and overweight sample compared to urban residents. Magnitudes of the differences vary slightly in the subdivided samples, but the absence of any notable differences between the two groups suggests that the systematic differences in body perception among rural and suburban residents are robust to BMI level. Therefore, results persist throughout the BMI distribution.

While insightful, the findings in this study are subject to some limitations. All height and weight data are self-reported. Evidence shows that women tend to underreport their weight more than males [61]. Additionally, the weight perception reported by females may also suffer from a tendency to underreport. Similar gender differences were found in the US National Health and Nutrition Examination Survey when comparing reported to measured weight and height information [50]. Not only is height and weight data subject to reporting, but BMI is also a subpar indicator of body fat composition since different subpopulations may have different tissue densities. A high BMI could be mistakenly classified as overweight if it belongs to an active, muscular individual with a high, lean body mass [62,63]. While the findings of this study shed light on adolescent body perception accuracy, more research utilizing measured height and body weight comparisons are needed to fully understand adolescents' weight perception. Another limitation of this study is the fact that interviews were conducted verbally. When asked about body weight in a verbal interview, respondents could experience a tendency to report answers that sound more pleasing or favorable.

\section{DISCUSSION AND CONCLUSION}

This study utilizes a measure of body perception that focuses accuracy relative to actual BMI. Over or under estimation was identified by comparing calculated BMI categories to reported body size. By examining both overestimation and underestimation of body weight, this study identified trends in adolescent weight perception more precisely than previous analyses. Results showed that the misestimation of body size was common among all ages, weights, races, ethnicities and sociodemographic levels.

Nearly half of adolescents misestimate their body weight and that discordant perception is more prevalent among men, blacks, younger adolescents, those enrolled in school and overweight individuals. The type of discordance or misestimating varies by residential locations. The findings show that rural residents are less likely than urban residents to overestimate their weight while suburban residents are more like to underestimate their body weight [64]. Males were three times more likely to overestimate their weight status than females. Blacks overestimated their weight, but Hispanics showed a tendency to underestimate.

Underestimation is problematic because it can signify that actual overweight is being ignored. The fact that underestimation is more prevalent with suburban residents and some minorities are of special concern as there is a higher prevalence of obesity in those same groups [65]. If underestimation negatively affects the efficacy of obesity intervention efforts, such patterns of underestimation across subgroups may increase the current disparities in the prevalence of obesity among subgroups.

On the other hand, blacks, rural residents and overweight residents, were more likely to overestimate their body weight. While body dissatisfaction may motivate overweight youth to eat healthier, if body composition does not 
change rapidly, they may turn to steroid use, over exercising, fasting, smoking, purging and fad diets to achieve results more quickly [66,67]. The public health concern about obesity may increase the proclivity for risky weight-related behaviors.

Perception integrates both a body image ideal and a situation norm capturing how one feels in relation to both the ideal and the norm. While the population is coming increasingly more overweight, the images displayed in the media are increasingly unattainable. At a time when adolescents are still growing both physically and mentally, it is becoming increasingly more difficult to reconcile what is both biologically healthy and visually pleasing. As self-image continues to develop, it is important that weight perception form an accurate estimation of weight and size. Both over and underestimation of body weight, can lead to unhealthy behaviors, situations and ideas.

\section{REFERENCES}

[1] Tremblay, L., \& Limbos, M. (2009). Body Image Disturbance and Psychopathology in Children: Research Evidence and Implications for Prevention and Treatment. Current Psychiatry Reviews, 5(1), 62-72. doi:10.2174/ 157340009787315307

[2] Cheung, P., Ip, P., Lam, S. T., \& Bibby, H. (2007). A study on body weight perception and weight control behaviours among adolescents in Hong Kong. Hong Kong Medical Journal, 13(1), 16-21.doi:10.3325/ cmj.2008.2.233.

[3] Sijtsema, S. (2003). Your health!?: Transforming health perception into food product characteristics in consumer-oriented product design (Unpublished master's thesis). Proefschrift Wageningen Universiteit.

[4] Gregory, C. O., Blanck, H. M., Gillespie, C., Maynard, L. M., \& Serdula, M. K. (2008). Health Perceptions and Demographic Characteristics Associated with Underass essment of Body Weight. Obesity, 16(5), 979986. doi:10.1038/ oby.2008.22.

[5] Kim, K. H. (2007). Religion, weight perception, and weight control behavior. Eating Behaviors, 8(1), 121-131. doi:10.1016/j.eat beh.2006.03.001.

[6] Johnson, J. L., Ratner, P. A., \& Bottorff, J. L. (1995). Canadian Journal of Public Health, 86(2), 103-108.

[7] Kobus, K. (2003). Peers and adolescent smoking. Addiction, 98, 37-55. doi:10.1046/j. 1360-0443.98.s1.4.

[8] Akers, R. L. (1998). Social learning and social structure: A general theory of crime and deviance. Boston, MA: Northeastern University Press.

[9] Bandura, A. (1977). Social learning theory. Englewood Cliffs, NJ: Prentice-Hall.

[10] Oetting, E. R., \& Donnermeyer, J. F. (1998). Primary Socialization Theory: The Etiology of Drug Use and Deviance. I. Substance Use \& Misuse, 33(4), 995-1026. doi:10.3109/10826 089809056252

[11] Leinhardt, S. (1977). Social network research [editor's introduction]. Journal of Mathematic al Sociology, 5, 1-4.

[12] Ennett, S. T., \& Bauman, K. E. (1993). Peer Group Structure and Adolescent Cigarette Smoking: A Social Network Analysis. Journal of Health and Social Behavior,34(3), 226-236. doi: $10.2307 / 2137204$.

[13] Wasserman, S., \& Faust, K. (1994). Social network analysis: Methods and applications. New York, NY: Cambridge University Press.

[14] Raudsepp, L., \&Viira, R. (2000). Sociocultural Correlates of Physical Activity in Adolescents. Pediatric Exercise Science, 12(1), 51-60. doi:10.1123/pes.12.1.51

[15] Unger, J. B., Yan, L., Shakib, S., Rohrbach, L. A., Chen, X., Qian, G., . . Johnson, C. (2002). Peer Influences and Access to Cigarettes as Correlates of Adolescent Smoking: A CrossCultural Comparison of Wuhan, China, and California. Preventive Medicine,34(4), 476484. doi:10.1006/pmed.2001.0996

[16] Vries, H. D. (2003). Parents and friends smoking status as predictors of smoking onset: Findings from six European countries. Health Education Research,18(5), 627-636.doi:10.10 93/her/cyg032

[17] Felts, W. M., Parrillo, A. V., Chenier, T., \& Dunn, P. (1996). Adolescents perceptions of relative weight and self-reported weight-loss activities: Analysis of 1990 YRBS national data. Journal of Adolescent Health, 18(1), 2026. doi:10.1016/1054-139x(95)00046-u.

[18] Reel, J., Voelker, D., \& Greenleaf, C. (2015). Weight status and body image perceptions in adolescents: Current perspectives. Adolescent Health, Medicine and Therapeutics, 6, 149158. doi:10.2147/ahmt.s68344

[19] Baranowski, T., Cullen, K. W., Nicklas, T., Thompson, D., \& Baranowski, J. (2003). Are Current Health Behavioral Change Models Helpful in Guiding Prevention of Weight Gain Efforts? Obesity Research, 11(S10), 23S-43S. doi:10.1038/oby.2003.222

[20] Simons-Morton, B., Haynie, D. L., Crump, A. D., Eitel, P., \& Saylor, K. E. (2001). Peer and Parent Influences on Smoking and Drinking among Early Adolescents. Health Education \& Behavior,28(1), 95-107. doi:10.1177/1090198 10102800109 
[21] Flay, B. R., Phil., D., Hu, F. B., \& Richardson, J. (1998). Psychosocial Predictors of Different Stages of Cigarette Smoking among High School Students. Preventive Medicine,27(5), A9-A18. doi:10.1006/pmed.1998.0380

[22] Paxton, R. J., Valois, R. F., \&Drane, J. W. (2004). Correlates of Body Mass Index, Weight Goals, and Weight-Management Practices Among Adolescents. Journal of School Health,74(4), 136-143. doi:10.1111/ j.174 6-1561.2004.tb06617.x

[23] Felton, G. M., Dowda, M., Ward, D. S., Dishman, R. K., Trost, S. G., Saunders, R., \& Pate, R. R. (2002). Differences in Physical Activity Between Black and White Girls Living in Rural and Urban Areas. Journal of School Health,72(6), 250-255. doi:10.1111/ j.1 746-1561.2002.tb07338.x

[24] Yost, J., Krainovich-Miller, B., Budin, W., \& Norman, R. (2010). Assessing weight perception accuracy to promote weight loss among U.S. female adolescents: A secondary analysis. BMC Public Health,10(1), 465. doi:10.1186/1471-2458-10-465

[25] Edwards, N. M., Pettingell, S., \&Borowsky, I. W. (2010). Where Perception Meets Reality: Self-Perception of Weight in Overweight Adolescents. Pediatrics, 125(3),E452-E458. doi:10.1542/peds.2009-0185

[26] Chung, A. E., Perrin, E. M., \& Skinner, A. C. (2013). Accuracy of Child and Adolescent Weight Perceptions and Their Relationships to Dieting and Exercise Behaviors: A NHANES Study. Academic Pediatrics,13(4), 371-378. doi:10.1016/j.acap.2013.04.011

[27] Fan, M., \&Jin, Y. (2015). The Effects of Weight Perception on Adolescents' WeightLoss Intentions and Behaviors: Evidence from the Youth Risk Behavior Surveillance Survey. International Journal of Environment al Research and Public Health, 12(11),1464014668.doi:10.3390/ije rph1211 14640

[28] Welch, C., Gross, S. M., Bronner, Y., Dewberry-Moore, N., \& Paige, D. M. (2004). Discrepancies in body image perception among fourth-grade public school children from urban, suburban, and rural Maryland. Journal of the American Dietetic Association, 104(7), 1080-1085. doi:10.1016/j.jada.2004.04.019

[29] Cole, M., \& Cole, S. R. (1996). The development of children. New York, NY: WH Freeman and Company.

[30] Steinberg, L. D. (1993). Adolescence. New York, NY: McGraw-Hill Education.

[31] Calzo, J. P., Sonneville, K. R., Haines, J., Blood, E. A., Field, A. E., \& Austin, S. B. (2012). The Development of Associations Among Body Mass Index, Body
Dissatisfaction, and Weight and Shape Concern in Adolescent Boys and Girls. Journal of Adolescent Health,51(5), 517-523. doi:10.1016 /j.jadohealth.2012.02. 021

[32] Kuchler, F., \&Variyam, J. N. (2003). Mistakes were made: Misperception as a barrier to reducing overweight. International Journal of Obesity,27(7), 856-861. doi:10.1038/ sj.ijo. 0802293

[33] Harris, K. (2013). The Add Health Study: Design and Accomplishments. The National Longitudinal Study of Adolescent Health. doi:10.17615/C6TW87

[34] Horm, J. (1993). Who in America Is Trying To Lose Weight? Annals of Internal Medicine, 119, 672-676. doi:10.7326/0003-4819-1197_part_2-199310011-00009

[35] Pritchard, M. E., King, S. L., \&Czajka-Narins, D. M. (1997). Adolescent body mass indices and self-perception. Adolescence,32, 863-880.

[36] Powell, A. D., \& Kahn, A. S. (1995). Racial differences in womens desires to be thin. International Journal of Eating Disorders, 17(2), 191-195. doi:10.1002/1098108x(199503)17:23.0.co;2-z

[37] Neff, L. J., Sargent, R. G., Mckeown, R. E., Jackson, K. L., \& Valois, R. F. (1997). Black-White differences in body size perceptions and weight management practices among adolescent females. Journal of Adolescent Health, 20(6), 459-465. doi:10.1016/s1054-139x(96)00273-x

[38] Wilfley, D. E., Schreiber, G. B., Pike, K. M., Striegel-Moore, R. H., Wright, D. J., \& Rodin, J. (1996). Eating disturbance and body image: A comparison of a community sample of adult black and white women. International Journal of Eating Disorders,20(4), 377-387. doi:10. 1002/(sici)1098-108x(1996 12)20: 43.0 .co;2k

[39] Rucker, C. E., \& Cash, T. F. (1992). Body images, body-size perceptions, and eating behaviors among African-American and white college women. International Journal of Eating Disorders, 12(3), 291-299. doi:10.1002/ 1098-108x(199211)12:33.0.co;2-a

[40] Dawson, D. A. (1988). Ethnic differences in female overweight: Data from the 1985 National Health Interview Survey. American Journal of Public Health,78(10), 1326-1329. doi:10.2105/ajph.78.10.1326

[41] Stevens, J., Kumanyika, S. K., \& Keil, J. E. (1994). Attitudes toward body size and dieting: Differences between elderly black and white women. American Journal of Public Health,84(8), 1322-1325. doi:10.2105/ajph. 84 8.1322

[42] Wong, S. L., \& Leatherdale, S. T. (2009). Association between sedentary behavior, 
physical activity, and obesity: Inactivity among active kids. Prevention of Chronic Disease,6(1), A26.

[43] Potter, B., Pederson, L., Chan, S., Aubut, J., \&Koval, J. (2004). Does a relationship exist between body weight, concerns about weight, and smoking among adolescents? An integration of the literature with an emphasis on gender. Nicotine \& Tobacco Research,6(3), 397-425.doi:10.1080/146222004100016965 29

[44] French, S. A., \& Jeffery, R. W. (1995). Weight concerns and smoking: A literature review. Annals of Behavioral Medicine,17(3), 234-244. doi:10.1007/bf02903918

[45] Rand, C. S., \&Kuldau, J. M. (1990). The epidemiology of obesity and self-defined weight problem in the general population: Gender, race, age, and social class. International Journal of Eating Disorders,9(3), 329-343. doi:10.1002/1098108x(199005)9:33.0.co;2-b

[46] Stephenson, M. G., Levy, A. S., Sass, N. L., \& McGarvey, W. E. (1987). 1985 NHIS findings: Nutrition knowledge and baseline data for the weight-loss objectives. Public Health Reports, 102, 61-67.

[47] Cavill, N., Biddle, S., \&Sallis, J. F. (2001). Health Enhancing Physical Activity for Young People: Statement of the United Kingdom Expert Consensus Conference. Pediatric Exercise Science,13(1), 12-25. doi:10.1123/pe s.13.1.12

[48] Anderson, C. (2000). Patterns of adolescent smoking initiation rates by ethnicity and sex. Tobacco Control,9(suppl 2), 4ii-8. doi:10. 1136/tc.9.suppl_2.ii4

[49] Forman, M. R., Trowbridge, F. L., Gentry, E. M., Marks, J. S., \&Hogelin, G. C. (1986). Overweight adults in the United States: The behavioral risk factor surveys. The American Journal of Clinical Nutrition,44(3), 410-416. doi:10.1093/ajcn/44.3.410

[50] Strauss, R. S. (1999). Self-reported Weight Status and Dieting in a Cross-sectional Sample of Young Adolescents. Archives of Pediatrics \& Adolescent Medicine,153(7), 741-747. doi:10.1001/archpedi.153.7.741

[51] Serdula, M. K. (1993). Weight Control Practices of U.S. Adolescents and Adults. Annals of Internal Medicine,119(7), 667-671. doi:10.7326/0003-4819-119- 7_par t_2-199310011-00008

[52] Jeffery, R. W., Folsom, A. R., Luepker, R. V., Jacobs, D. R., Gillum, R. F., Taylor, H. L., \& Blackburn, H. (1984). Prevalence of overweight and weight loss behavior in a metropolitan adult population: The Minnesota Heart Survey experience. American Journal of
Public Health,74(4), 349-352. doi:10.2105/aj ph.74.4.349

[53] Williamson, D. F., Serdula, M. K., Anda, R. F., Levy, A., \& Byers, T. (1992). Weight loss attempts in adults: Goals, duration, and rate of weight loss. American Journal of Public Health, 82(9), 1251-1257. doi:10.2105/ajph.82 .9 .1251

[54] Bennett, E. M. (1991). Weight-loss practices of overweight adults. The American Journal of Clinical Nutrition,53(6), 1519-1521.doi:10.10 93/ajcn/53.6.1519s

[55] Levy, A. S. (1993). Weight Control Practices of U.S. Adults Trying to Lose Weight. Annals of Internal Medicine,119(7), 661-666. doi:10.7326/0003-4819-119-7_part_2-199310 011-00007

[56] Fitzgibbon, M. L., Blackman, L. R., \&Avellone, M. E. (2000). The Relationship Between Body Image Discrepancy and Body Mass Index Across Ethnic Groups. Obesity Research,8(8), 582-589. doi:10.1038/ oby.200 0.75

[57] Nawaz, H., Chan, W., Abdulrahman, M., Larson, D., \& Katz, D. L. (2000). Selfreported weight and height: Implications for obesity research. American Journal of Preventive Medicine,20, 294-298.

[58] Kuskowska-Wolk, K., Karlsson, P., Stolt, M., \&Rossner, S. (1989). The predictive validity of body mass index based on self-reported weight and height. International Journal of Obesity, 13, 441-453.

[59] Weber, B., Fannin, J. M., Miller, K., \& Goetz, S. (2018). Intergenerational mobility of low-income youth in metropolitan and non-metropolitan America: A spatial analysis. Regional Science Policy \& Practice, 10(2), 87101.

[60] Okop, K. J., Mukumbang, F. C., Mathole, T., Levitt, N., \&Puoane, T. (2016). Perceptions of body size, obesity threat and the willingness to lose weight among black South African adults: a qualitative study. BMC public health, 16(1), 365.

[61] Sherry, B., Jefferds, M. E., \&GrummerStrawn, L. M. (2007). Accuracy of adolescent self-report of height and weight in assessing overweight status: a literature review. Archives of pediatrics \& adolescent medicine, 161(12), 1154-1161.

[62] Daniels, S. R., Khoury, P. R., \& Morrison, J. A. (1997). The utility of body mass index as a measure of body fatness in children and adolescents: differences by race and gender. Pediatrics, 99(6), 804-807.

[63] Viner, R. M., Haines, M. M., Taylor, S. J. C., Head, J., Booy, R., \&Stansfeld, S. (2006). Body mass, weight control behaviours, weight 
perception and emotional well-being in a multiethnic sample of early adolescents. International journal of obesity, 30(10), 1514.

[64] Bergström, E., Stenlund, H., \&Svedjehäll, B. (2000). Assessment of body perception among Swedish adolescents and young adults. Journal of Adolescent Health, 26(1), 70-75.

[65] Lutfiyya, M. N., Lipsky, M. S., Wisdom-Behounek, J., \&Inpanbutr-Martinkus, M. (2007). Is rural residency a risk factor for overweight and obesity for US children? Obesity, 15(9), 2348-2356.

[66] Striegel-Moore, R. H., \&Smolak, L. E. (2001). Eating disorders: Innovative directions in research and practice. American Psychological Association.

[67] Martz, D. M., Handley, K. B., \& Eisler, R. M. (1995). The relationship between feminine gender role stress, body image, and eating disorders. Psychology of Women Quarterly, 19(4), 493-508.

Citation: Molly M. Jacobs. Adolescent Body Perception: Urban, Rural and Suburban Differences. Effect of High BMI on Endometriosis - A Chart Review Study. ARC Journal of Public Health and Community Medicine. 2019; 4(1):6-19.DOI:dx.doi.org/10.20431/2456-0596.0401002.

Copyright: (C) 2019 Authors. This is an open-access article distributed under the terms of the Creative Commons Attribution License, which permits unrestricted use, distribution, and reproduction in any medium, provided the original author and source are credited. 